\title{
CCCTC-Binding Factor Locks Premature IgH Germline Transcription and Restrains Class Switch Recombination
}

\author{
Ester Marina-Zárate ${ }^{\dagger}$, Arantxa Pérez-Garcia ${ }^{\dagger, \neq}$ and Almudena R. Ramiro* \\ B Lymphocyte Biology Laboratory, Fundacion Centro Nacional de Investigaciones Cardiovasculares Carlos III, Madrid, Spain
}

\section{OPEN ACCESS}

Edited by:

Deborah K. Dunn-Walters,

University of Surrey,

United Kingdom

Reviewed by:

Michael Zemlin,

Universitätsklinikum des

Saarlandes, Germany

Paolo Casali,

The University of Texas Health

Science Center San Antonio,

United States

*Correspondence:

Almudena R. Ramiro aramiro@cnic.es

tThese authors have contributed equally to this work.

fPresent address: Arantxa Pérez-García, Epigenetics of Cancer and Ageing Group, Cancer Research UK Beatson Institute, Glasgow, United Kingdom

Specialty section: This article was submitted to B Cell Biology,

a section of the journal

Frontiers in Immunology

Received: 19 June 2017 Accepted: 18 August 2017 Published: 04 September 2017

Citation:

Marina-Zárate E, Pérez-García A and Ramiro AR (2017) CCCTC-Binding

Factor Locks Premature IgH Germline Transcription and Restrains

Class Switch Recombination.

Front. Immunol. 8:1076. doi: 10.3389/fimmu.2017.01076
In response to antigenic stimulation B cells undergo class switch recombination (CSR) at the immunoglobulin heavy chain $(\mathrm{lgH})$ to replace the primary $\operatorname{lgM} / \mathrm{lgD}$ isotypes by $\operatorname{lgG}$, IgE, or IgA. CSR is initiated by activation-induced cytidine deaminase (AID) through the deamination of cytosine residues at the switch (S) regions of $\mathrm{IgH}$. B cell stimulation promotes germline transcription (GLT) of specific $S$ regions, a necessary event prior to CSR because it facilitates AID access to S regions. Here, we show that CCCTCbinding factor (CTCF)-deficient mice are severely impaired in the generation of germinal center B cells and plasma cells after immunization in vivo, most likely due to impaired cell survival. Importantly, we find that CTCF-deficient B cells have an increased rate of CSR under various stimulation conditions in vitro. This effect is not secondary to altered cell proliferation or AID expression in CTCF-deficient cells. Instead, we find that CTCF-deficient $\mathrm{B}$ cells harbor an increased mutation frequency at switch regions, probably reflecting an increased accessibility of AID to $\mathrm{IgH}$ in the absence of CTCF. Moreover, CTCF deficiency triggers premature GLT of $S$ regions in naïve B cells. Our results indicate that CTCF restricts CSR by enforcing GLT silencing and limiting AID access to $\lg \mathrm{H}$.

Keywords: class switch recombination, СCCTC-binding factor, germline transcription, activation-induced deaminase, somatic hypermutation

\section{INTRODUCTION}

B cells remodel their immunoglobulin genes first as part of their differentiation program in the bone marrow, and then during the immune response, in the context of germinal centers (1). In the bone marrow, the heavy (IgH) and the light chain (IgL) immunoglobulin genes are subject to $\mathrm{V}(\mathrm{D}) \mathrm{J}$ recombination, a site specific recombination reaction triggered by RAG recombinases $(2,3)$. Subsequently, B cells that have been activated by antigen engage in the germinal center reaction where immunoglobulin genes are further diversified by somatic hypermutation (SHM) and class switch recombination (CSR), both of which are initiated by the activation-induced cytidine deaminase (AID) enzyme (4-6). SHM introduces (mostly) point mutations in the antigen recognizing, variable region of the IgH and IgL genes and antibody variants with higher affinity for antigen are selected through iterative rounds of mutation, proliferation, and cell death (7). CSR is a region-specific recombination reaction whereby the primary $\mu$ constant region $(\mathrm{C} \mu)$ is replaced by a downstream constant region $(\mathrm{C} \gamma, \mathrm{C} \varepsilon$, or $\mathrm{C} \alpha)$ in the IgH gene, such that 
the primary $\operatorname{Ig} M / \operatorname{IgD}$ isotypes switch to $\operatorname{IgG}, \operatorname{IgE}$, or $\operatorname{Ig} A(8,9)$. Highly repetitive sequences called switch $(S)$ regions preceding each constant region are targeted by AID, which triggers the deamination of cytosines followed by the generation of double strand breaks and the recombination reaction. CSR to a particular isotype is determined by stimulation-driven cues that activate specific $S$ region I promoters, inducing their germline transcription (GLT) (10). GLT of both the donor and acceptor $S$ regions is an absolute requirement for CSR, presumably by promoting transcription-coupled AID recruitment (11).

Both $\mathrm{V}(\mathrm{D}) \mathrm{J}$ recombination and CSR are tightly developmentally regulated, are intimately linked to transcription, and involve the formation of long-range DNA loops that facilitate the interaction between distant cis regulatory regions. CCCTCbinding factor (CTCF) is an architectural protein that regulates the genome function by mediating interactions between distant DNA sequences $(12,13)$ and is known to act as a transcriptional insulator through the generation of chromatin loops (14-16). CTCF regulates bone marrow $B$ cell differentiation at different levels. First, CTCF-deficient pre-B cells show impaired proliferation and differentiation (17). Further, CTCF mediates interactions between distal and proximal regions of the $\operatorname{IgH}$ locus, regulating its transcription (18), and CTCF-binding elements (CBEs) are critical to inhibit rearrangement of proximal $\mathrm{V}_{\mathrm{H}}$ genes and promoting rearrangement of distal $\mathrm{V}_{\mathrm{H}}$ genes $(19,20)$. Finally, IgH employs CBE-based subdomains to regulate RAG on- and off-target activity (21). Regarding the role of CTCF during the germinal center reaction, we have recently shown that CTCF is an essential transcriptional regulator that allows high proliferation rate of germinal center B cells and represses the expression of Blimp-1, thus preventing plasma cell differentiation (22). However, the role of CTCF in CSR is not completely understood. The IgH locus is flanked by a $3^{\prime}$ regulatory region $\left(3^{\prime} \mathrm{RR}\right)$, located $3^{\prime}$ of the most downstream $\mathrm{C}_{\mathrm{H}}$, the $\mathrm{C} \alpha$ gene $(23,24)$. The proximal $3^{\prime} \mathrm{RR}$ contains several B cell-specific enhancers (hs3a, hs1,2, hs3b, and hs4) that are required for $\operatorname{IgH}$ GLT, class switching to all isotypes and high levels of Ig transcription in plasma cells (25-27). The distal $3^{\prime} \mathrm{RR}$ enhancer region (containing hs5, 6, 7, and 38 enhancers) is densely riveted with CBEs, and deletion of hs5-7 (harboring seven of the nine CBEs at the distal $3^{\prime} \mathrm{RR}$ ) affected IgH locus compaction and $\mathrm{V}_{\mathrm{H}}$ usage during $\mathrm{V}(\mathrm{D}) \mathrm{J}$ recombination, but did not affect CSR (28). In contrast, a CBE has been very recently identified within the $\mathrm{C} \alpha$ gene whose deletion promotes isotype-specific GLT in developing and resting B cells and alters CSR (29).

Here, we have directly assessed the role of CTCF in CSR using a conditional mouse model for CTCF depletion in B cells. We find that CTCF-deficient B cells show increased rate of CSR to various isotypes and under various stimulation conditions. This effect was not related to any measurable alterations of cell cycle or proliferation and was not a consequence of increased levels of AID expression. Instead, we find that AID activity is quantitatively increased on S regions. Finally, we show that GLT is markedly increased from activation-inducible, acceptor $S$ regions in CTCF-deficient naïve B cells, indicating that CTCF restricts the transcription of activation-inducible $S$ regions and limits AID accessibility and CSR.

\section{MATERIALS AND METHODS}

\section{Mice and Immunization}

CCCTC-binding factor-deficient mice were obtained by breeding $\mathrm{CTCF}^{\mathrm{f} / \mathrm{fl}}$ mice (30) with CD19-Cre $\mathrm{ki}^{\mathrm{k} /+}$ (31) mice. In all the experiments, $\mathrm{CTCF}^{\mathrm{H} /+}$; CD19-Cre $\mathrm{ki}^{\mathrm{k} /+}$ littermates were used as controls. Both males and females were used for experiments. All animals were housed in specific pathogen-free conditions, under a $12 \mathrm{~h}$ dark/light cycle with food ad libitum. All animal procedures were conducted according to EU Directive 2010/63/ UE, enforced in Spanish law under Real Decreto 53/2013. The procedures have been reviewed by the Institutional Animal Care and Use Committee (IACUC) of Centro Nacional de Investigaciones Cardiovasculares and approved by Consejeria de Medio Ambiente, Administración Local y Ordenación del Territorio of Comunidad de Madrid (Ref: PROEX 341/14).

T-dependent immunization was induced in 6-11 weeks

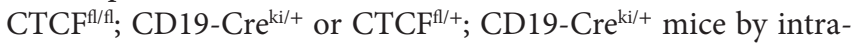
venously injection of $10^{8}$ sheep red blood cells resuspended in $100 \mu \mathrm{l}$ of sterile PBS. Immunization response was analyzed in spleen 7 days after sheep red blood cell injection. Number of animals per group to detect biologically significant effect sizes was calculated using appropriate statistical sample size formula and indicated in the biometrical planning section of the animal license submitted to the governing authority.

\section{Cell Cultures}

Primary B cells from CTCF ${ }^{\mathrm{f} / \mathrm{fl}}$; CD19-Cre $\mathrm{C}^{\mathrm{ki} /+}$ or $\mathrm{CTCF}^{\mathrm{f} /+}$; CD19$\mathrm{Cre}^{\mathrm{ki} /+}$ mice were isolated from spleen by immunomagnetic depletion using anti-CD43 beads (Miltenyi Biotec). Purified $\mathrm{B}$ cells were cultured at a final concentration of $1.2 \times 10^{6} \mathrm{cell} /$ $\mathrm{ml}$ in complete RPMI supplemented with $10 \%$ of FBS, $50 \mathrm{mM}$ of 2- $\beta$ mercaptoethanol (Gibco), $20 \mathrm{mM}$ Hepes (Gibco) and $10 \mathrm{ng} / \mathrm{ml}$ of IL-4 (PeproTech) and $25 \mu \mathrm{g} / \mathrm{ml}$ of lipopolysaccharide (LPS, Sigma-Aldrich) or $1 \mu \mathrm{g} / \mathrm{ml}$ of anti-mouse CD40 (BD Pharmingen) and $10 \mathrm{ng} / \mathrm{ml}$ of IL-4 (PeproTech) to switch to IgG1; $25 \mu \mathrm{g} / \mathrm{ml}$ of LPS (Sigma-Aldrich) to switch to IgG3; $20 \mathrm{ng} / \mathrm{ml}$ of TGF- $\beta$ (RD Systems), $1 \mu \mathrm{g} / \mathrm{ml}$ of anti-mouse CD40 (BD Pharmingen), and $10 \mathrm{ng} / \mathrm{ml}$ of IL-4 (PeproTech) to switch to IgG2b.

\section{Flow Cytometry}

Single-cell suspensions were obtained from spleen or cultured $B$ cells and stained with fluorophore-conjugated anti-mouse or human antibodies (BD Pharmingen or Invitrogen) to detect B220 (RA3-6B2, 1/200), Fas (Jo2, 1/400), GL7 (1/200), CD138 (281-2, 1/200), immunoglobulin G1 (IgG1, A85-1, 1/400), immunoglobulin G3 (IgG3, R40-82, 1/200), and immunoglobulin G2b (IgG2b, RMG2b-1, 1/200). Cell death was assessed by Annexin $\mathrm{V}$ (BD Pharmingen) staining. DNA incorporation was measured by BrdU staining (FITC BrdU Flow Kit, BD Pharmingen). Proliferation was assessed by cell trace CFSE staining (Invitrogen). Proliferation index was calculated as total number of divisions that took place in the culture divided by number of cells that have undergone at least one cell division. Samples were acquired on LSRFortessa or FACSCanto instruments (BD Biosciences) and analyzed with FlowJo Software. 


\section{Next-Generation Sequencing}

Analysis of $S \mu$ mutations was performed as previously described (32). Briefly, DNA was extracted from LPS/IL-4 stimulated B cells from $\mathrm{CTCF}^{\mathrm{A} / \mathrm{fl}} ; \mathrm{CD} 19-\mathrm{Cre}^{\mathrm{ki} /+}(n=3)$ or $\mathrm{CTCF}^{\mathrm{A} /+}$; CD19-Cre ${ }^{\mathrm{k} / /+}$ $(n=3)$ mice. $\mathrm{S} \mu$ fragment was PCR amplified using the oligonucleotides (forward) 5' ${ }^{\prime}$-AAT GGA TAC CTC AGT GGT TTT TAA TGG TGG GTT TA- ${ }^{\prime}$ and (reverse) $5^{\prime}$-GCG GCC CGG CTC ATT CCA GTT CAT TAC AG-3'. Amplification reactions were carried out with $2.5 \mathrm{U}$ of Pfu Ultra (Stratagene) in a 50- $\mu$ l reaction with the following profile: $94^{\circ} \mathrm{C}$ for 5 min followed by 25 cycles at $94^{\circ} \mathrm{C}$ for $10 \mathrm{~s}, 60^{\circ} \mathrm{C}$ for $30 \mathrm{~s}$, and $72^{\circ} \mathrm{C}$ for $1 \mathrm{~min}$. PCR products from four independent reactions per mouse were pooled and NGS sequencing was performed by the Genomics Unit at CNIC. Briefly, Libraries were prepared using NEBNext Ultra DNA Library Prep (New England Biolabs) following manufacturer's instructions and sequenced on a HiSeq2500 (Illumina).

\section{qRT-PCR}

RNA was extracted from $\mathrm{CTCF}^{\mathrm{A} / \mathrm{f}}$; CD19-Cre $\mathrm{Cr}^{\mathrm{ki} /+}$ or $\mathrm{CTCF}^{\mathrm{A} /+}$; CD19-Cre $\mathrm{r}^{\mathrm{k} /+}$ mice using the Qiagen RNeasy kit and treated with DNAse. cDNA was synthesized using random hexamers (Roche) and SuperScript II reverse transcriptase. cDNA was quantified by SYBR green assay (Applied Biosystems) and normalized to GAPDH expression in duplicates. The following primers were used: mouse-GAPDH (forward) 5'-TGA AGC AGG CAT CTG AGG G-3' (reverse) 5'-CGA AGG TGG AAG AGT GGG AG-3'; mouse-CTCF (forward) 5'-CAC CTG GGT CCT AAC AGA ACA GA-3'; mouse-CTCF (reverse) 5'-AGT ATG AGA GCG AAT GTG TCG TTT-3', GLT-G1 (forward) 5'-TCG AGA AGC CTG AGG AAT GTG-3'; GLT-G1 (reverse) 5'-ATG GAG TTA GTT TGG GCA GCA-3'; GLT-G3 (forward) 5'-AGA GTC AGC CTC AAG GAG ATG AT-3'; GLT-G3 (reverse) 5'-CAG GGA CCA AGG GAT AGA CAG-3', GLT-G2b (forward) 5'-CCA ACC AGG AAG AGT CCA GAG-3'; GLT-G3b (reverse) 5'-ACA GGG ATC CAG AGT TCC AAG T-3'; mouse-AID (forward) $5^{\prime}$-ACC TTC GCA ACA AGT CTG GCT-3', mouse-AID (reverse) 5' AGC CTT GCG GTC TTC ACA GAA-3'.

\section{Immunoblotting}

$B$ cells from LPS/IL-4 cultures were incubated on ice for $20 \mathrm{~min}$ in RIPA lysis buffer in the presence of protease inhibitors (Roche), and lysates were cleared by centrifugation. Total protein was sizefractionated on SDS-PAGE 12\% acrylamide-bisacrylamide gels and transferred to Protran nitrocellulose membrane (Whatman) in transfer buffer $(0.19 \mathrm{M}$ glycine, $25 \mathrm{mM}$ Tris base, and $0.01 \%$ SDS) containing $20 \%$ methanol ( $90 \mathrm{~min}$ at $0.4 \mathrm{~A}$ ). Membranes were probed with anti-mouse-AID (1/25, eBioscience, 14-5959-82) and anti-mouse-MEK2 (1/2,000, BD Biosciences Pharmingen, 610,236). Then, membranes were incubated with HRP-conjugated anti-rat $(1 / 5,000$, Bethyl Laboratories, A110$105 \mathrm{P})$ and anti-mouse (1/10,000, DAKO) antibodies, respectively, and developed with Clarity ${ }^{\mathrm{TM}}$ Western ECL Substrate (Bio-Rad).

\section{Statistics}

Statistical analyses were performed with GraphPad Prism (version 6.01 for Windows, GraphPad Software, San Diego, CA, USA) using two-tailed Student's $t$-test for all parameters conforming to normal distributions (according to Shapiro-Wilk normality test). Variance similarity was assessed with $F$ test. $p \leq 0.05$ was considered statistically significant. Error bars in figures represent $\mathrm{SD}$.

\section{RESULTS}

To address the function of CTCF during CSR we generated a conditional mouse model to deplete CTCF late during B cell differentiation. $\mathrm{CTCF}^{\mathrm{A} / \mathrm{fl}}$ mice (30) were bred to $\mathrm{CD} 19-\mathrm{Cre}^{\mathrm{k} / /}$, where the Cre recombinase is progressively expressed in the bone marrow and allows full depletion of floxed alleles at late stages of $\mathrm{B}$ cell differentiation (31). $\mathrm{CTCF}^{\mathrm{A} / \mathrm{f}} ; \mathrm{CD} 19-\mathrm{Cre}^{\mathrm{k} /+}$ (CTCF-deficient mice, hereafter $\left.\mathrm{CTCF}^{\mathrm{A} / \mathrm{f}}\right)$ and $\mathrm{CTCF}^{\mathrm{A} /+} ; \mathrm{CD} 19-\mathrm{Cre}^{\mathrm{k} / /+}$ littermates (control mice, hereafter $\mathrm{CTCF}^{\mathrm{f} /+}$ ) were used in all experiments, since we have previously shown that CTCF is not haploinsufficient in mature B cells (22). We first analyzed the effect of CTCF depletion in Peyer's patches, where germinal centers are constitutively generated in response to antigens of the gut microbiota, and found that $\mathrm{CTCF}^{\mathrm{A} / \mathrm{fl}}$ Peyer's patches are almost completely devoid of germinal center B cells (Figure 1A). To analyze the role of CTCF in de novo germinal center formation, we immunized $C T C F^{\mathrm{A} / \mathrm{fl}}$ and $\mathrm{CTCF}^{\mathrm{A} / \mathrm{+}}$ mice with sheep red blood cells and analyzed spleen populations by flow cytometry 7 days after immunization. We found that both $\mathrm{Fas}^{+} \mathrm{GL7}^{+}$germinal center B cells and $\mathrm{CD} 138^{+}$ plasma cells were virtually absent in $\mathrm{CTCF}^{\mathrm{A} / \mathrm{l} / \mathrm{l}}$ mice (Figure 1B), further indicating that CTCF is absolutely required for germinal center formation, and concomitantly, for plasma cell generation. In vitro stimulation of spleen B cells in the presence of LPS and IL-4 revealed that $\mathrm{CTCF}^{\mathrm{A} / \mathrm{fl}}$ cells had a major B cell survival defect as measured by Annexin V staining (Figure 1C) and by viability stain exclusion (Figure 1D). Thus, these results suggest that CTCF is required for germinal center formation at least in part by enabling B cell survival.

We have previously generated a conditional mouse model where CTCF depletion is induced only upon AID expression [CTCF ${ }^{\mathrm{A} / \mathrm{fl}} ; \mathrm{AID}-\mathrm{Cre}^{\mathrm{TG} /+}$ mice (22)], i.e., delayed in comparison with the model presented here, where naïve $\mathrm{B}$ cells are already devoid of CTCF (Figure 1E). Consistently with the findings reported here, in $\mathrm{CTCF}^{\mathrm{f} / \mathrm{f}}$; AID-Cre ${ }^{\mathrm{TG} /+}$ mice CTCF is also essential for the germinal center reaction (22). In contrast, B cells from the AID-Cre and the CD19-Cre models widely differ in their response to in vitro stimulation: while CTCF depletion in $\mathrm{CTCF}^{\mathrm{A} / \mathrm{fl}}$; AID$\mathrm{Cre}^{\mathrm{TG} /+} \mathrm{B}$ cells did not lead to any measurable defect upon CSR stimulation by LPS + IL-4 (22), CTCF ${ }^{\mathrm{A} / \mathrm{fl}} ; \mathrm{CD} 19-\mathrm{Cre}^{\mathrm{k} /+} \mathrm{B}$ cells display a clear survival defect. Besides the functional implications of this disparity (discussed below), the $\mathrm{CTCF}^{\mathrm{A} / \mathrm{f}} ; \mathrm{CD} 19-\mathrm{Cr}^{\mathrm{k} / \mathrm{t}}$ model opens the possibility to study the function of CTCF in CSR, which could not be accurately addressed in $\mathrm{CTCF}^{\mathrm{A} / \mathrm{f}}$; $\mathrm{AID}-\mathrm{Cre}^{\mathrm{TG} /+}$ mice.

To assess the role of CTCF in CSR we stimulated spleen B cells from $\mathrm{CTCF}^{\mathrm{A} / \mathrm{l}}$ and $\mathrm{CTCF}^{\mathrm{A} /+}$ mice in vitro in the presence of LPS and IL-4 and measured CSR to IgG1 by flow cytometry analysis. We found that CTCF-deficient cells consistently showed increased rate of CSR at all analyzed time points (Figures 2A,B). To determine whether the enhancement of CSR in CTCF-deficient cells was restricted to the IgG1 isotype or to the specific conditions of LPS + IL-4 stimulation, we stimulated CTCF ${ }^{\mathrm{A} / \mathrm{fl}}$ and $\mathrm{CTCF}^{\mathrm{A} /+}$ 
A
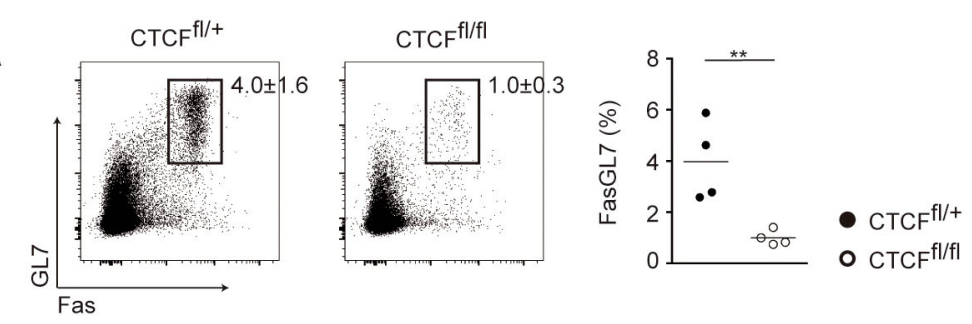

B
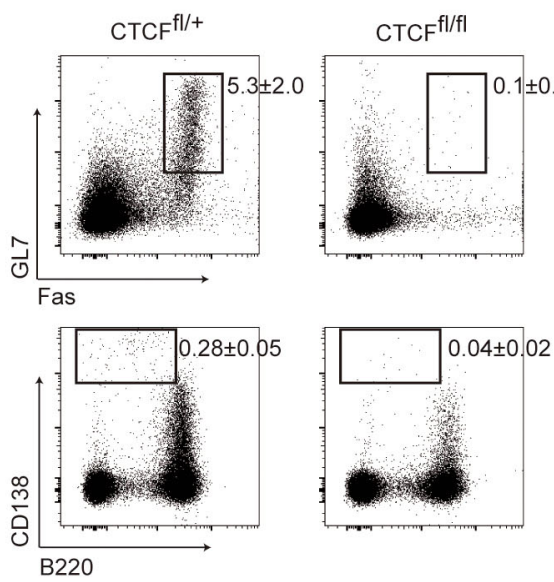

C
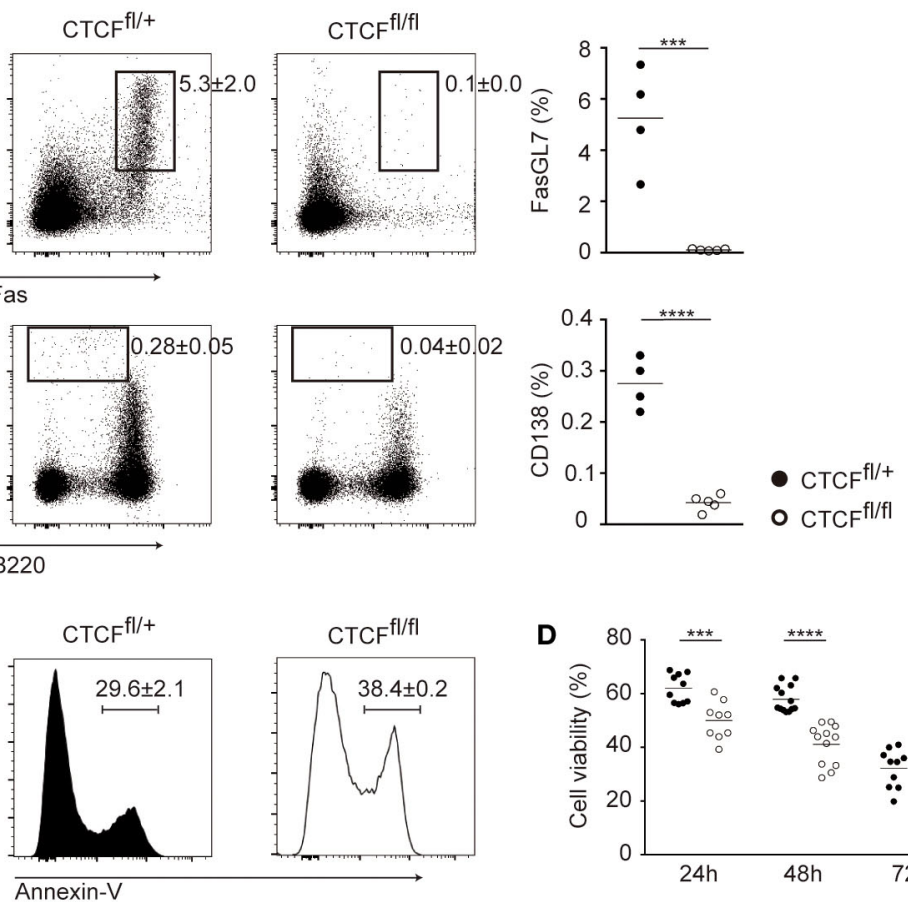

E

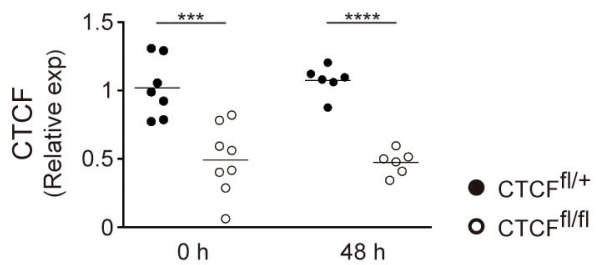

FIGURE 1 | CCCTC-binding factor (CTCF) is required for the germinal center reaction in CTCFi/fil CD19-Cre ${ }^{\mathrm{k} /+}$ mice. (A) Flow cytometry analysis of Fas and GL7 expression in Peyer's patch B cells from CTCF ${ }^{\mathrm{f} /+}(n=4)$ and $\mathrm{CTCF}^{\mathrm{f} / \mathrm{ll}}(n=4)$ mice. Representative B220 $\mathrm{O}^{+}$gated plots are shown on the left. Quantifications are shown on the right as percentage within $\mathrm{B} 220^{+}$cells. Each dot represents an individual mouse. p(Fas/GL7) = 0.01. (B) Flow cytometry analysis of GL7, Fas (top) and CD138, B220 (bottom) expression in splenic B cells from CTCF ${ }^{\mathrm{f} /+}(n=4)$ and $\mathrm{CTCF}^{\mathrm{f} / \mathrm{fl}}(n=5)$ mice 7 days after SRBC immunization. Plots are gated on B220+ cells (top) or on total alive cells (bottom). Quantifications are shown on the right. Each dot represents an individual mouse. $p($ Fas/GL7) $=0.0006 ; p$ (B220/ CD138) $<0.0001$. (C) Annexin V staining in $\mathrm{CTCF}^{1 / /}(n=2)$ and $\mathrm{CTCF}^{\mathrm{f} / \mathrm{fl}}(n=2)$ after $72 \mathrm{~h}$ of lipopolysaccharide (LPS) + IL-4 stimulation. A representative flow cytometry histogram is shown. Numbers indicate percentages \pm SD. (D) Quantification of viable cells $\left(7-A^{-} D^{-}\right)$by flow cytometry analysis in CTCFil/ $(n=15)$ and $\operatorname{CTCF}^{1 / / 1}(n=14)$ after LPS + IL-4 stimulation; $p(24 \mathrm{~h})<0.0001 ; p(48 \mathrm{~h})<0.0001$. Each point corresponds to B cell cultures from an individual mouse. (E) qRT-PCR analysis of CTCF expression in resting and activated B cells from CTCFil/ $(n=7)$ and CTCFilil $(n=8)$ mice. $p(0 \mathrm{~h})=0.0009 ; p(48 \mathrm{~h})<0.0001$. Statistical analysis was done with two-tailed unpaired Student's t-test.

B cells with anti-CD40 + IL-4, LPS, or TGF $\beta$ + anti-CD40 + IL-4, which preferentially trigger the activation of $\mathrm{I} \gamma 1$, I $\gamma 3$, and $\mathrm{I} \gamma 2 \mathrm{~b}$ $S$ region promoters and the switch to IgG1, IgG3, and IgG2b, respectively. All three stimulations resulted in a notable increase in CSR in $\mathrm{CTCF}^{\mathrm{f} / \mathrm{fl}}$ cells, indicating that CTCF deficiency broadly enhances the rate of CSR, regardless of the activation stimulus or the particular $S$ region being used in the recombination reaction (Figure 2C). Thus, our results indicate that CTCF restricts the extent of CSR during B cell activation.

Class switch recombination is tightly associated with proliferation $(9,33)$, such that B cells that have undergone more cell divisions accumulate a bigger fraction of isotype-switched cells. To 

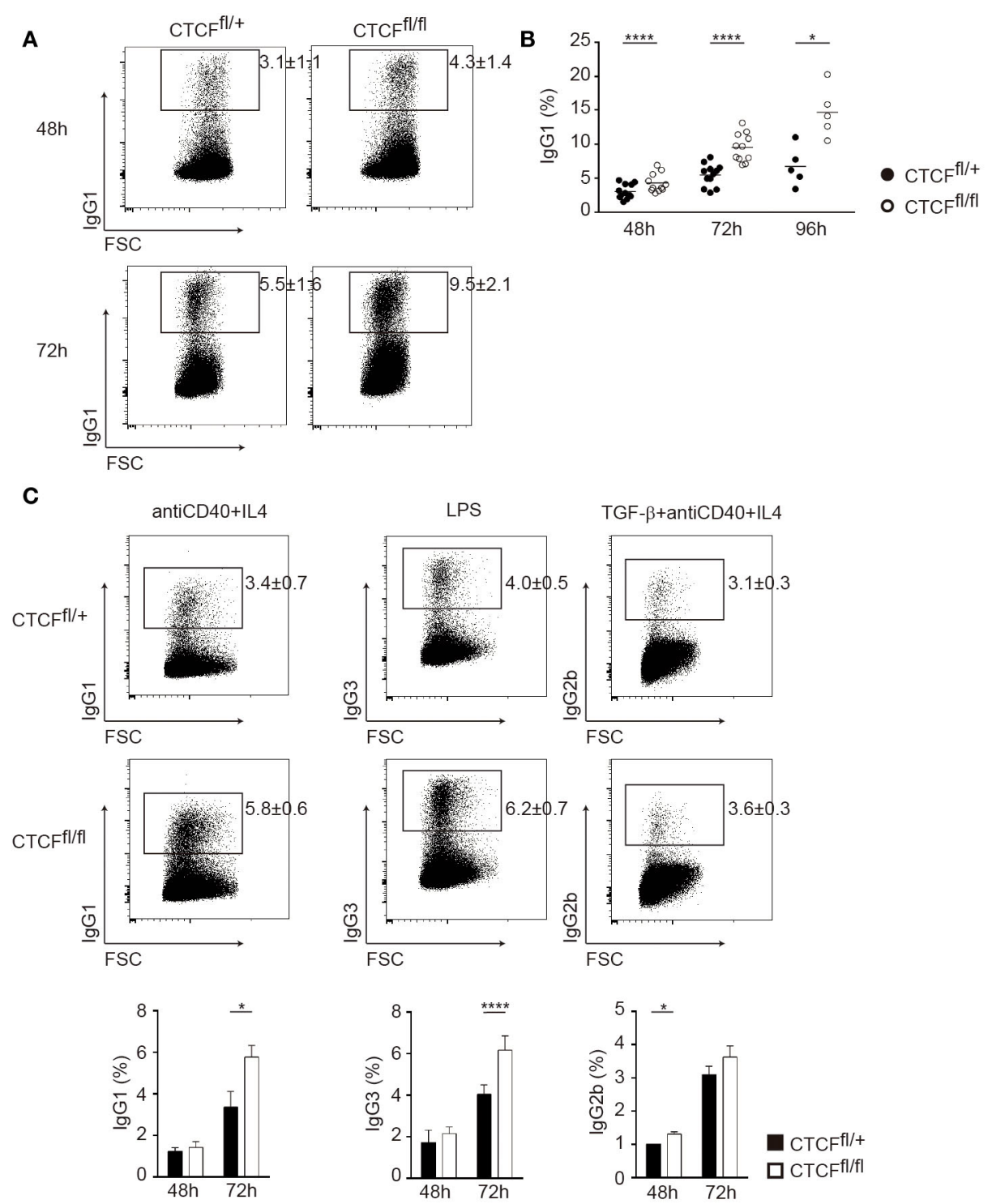

FIGURE 2 | CCCTC-binding factor (CTCF) deficiency increases the rate of class switch recombination (CSR) in vitro. (A) Representative flow cytometry analysis of surface lgG1 expression 1 in splenic B cells from CTCF ${ }^{\mathrm{f} /+}$ and CTCFil/l mice after $48 \mathrm{~h}$ (top panels) and $72 \mathrm{~h}$ (bottom panels) of lipopolysaccharide (LPS) + IL-4 stimulation. (B) Quantification of IgG1 cells in $\mathrm{CTCF}^{\mathrm{fl} /+}(n=12)$ and $\mathrm{CTCF}^{\mathrm{f} / \mathrm{l}}(n=11) \mathrm{B}$ cells. Each dot corresponds to a B cell culture from an individual mouse. Time of analysis is indicated underneath. Mean values are indicated in horizontal. $p(48 \mathrm{~h})<0.0001 ; p(72 \mathrm{~h})<0.0001 ; p(96 \mathrm{~h})=0.0119$. (C). Representative flow cytometry analysis (top) of surface expression of CSR in splenic B cells from CTCF fl/+ $(n=4)$ and CTCF ${ }^{f / / 1}(n=4)$ mice after 72 h of anti-CD40 + IL-4 (left), LPS (middle), and TGF $\beta+$ anti-CD40 + IL-4 (right) stimulation. Quantification of IgG 48 and $72 \mathrm{~h}$ after stimulation is shown on the bottom. $p$ (anti-CD40 + IL-4) = 0.0022; $p(\mathrm{LPS})=0.0021 ; p(\mathrm{TGF} \beta+$ anti-CD40 $+\mathrm{IL}-4)=0.033$. Statistical analysis was done with two-tailed unpaired Student's $t$-test.

investigate whether the increased rate of CSR could be secondary to an alteration in cell proliferation, we first performed cell cycle analysis of $\mathrm{CTCF}^{\mathrm{A} / \mathrm{l}}$ and $\mathrm{CTCF}{ }^{\mathrm{A} / \mathrm{+}} \mathrm{B}$ cells stimulated with LPS + IL-4. We could not detect any alteration in the proportion of cells in G1, $\mathrm{S}$, or $\mathrm{G} 2 / \mathrm{M}$ as measured by BrdU incorporation (Figure 3A). The rate of cell proliferation analyzed by CFSE dilution and the proliferation index were also indistinguishable between $\mathrm{CTCF}^{\mathrm{f} / \mathrm{fl}}$ and $\mathrm{CTCF}^{\mathrm{f} /+} \mathrm{LPS}+\mathrm{IL}-4$ stimulated B cells (Figures 3B,C). Further, we measured the rate of CSR to IgG1 as a function of the number of cell divisions, and we found that $\mathrm{CTCF}^{\mathrm{f} / \mathrm{fl}}$ cells display an enhanced CSR frequency compared to $\mathrm{CFCF}^{\mathrm{A} /+}$ cells, regardless of the number of divisions they have undergone (Figure 3D). Together, these observations indicate that the increased CSR rate observed in CTCF-deficient B cells is not a collateral effect of cell proliferation alterations and instead it suggests that it could be intrinsically related to the molecular mechanism of CSR.

Activation-induced cytidine deaminase initiates CSR by deaminating cytosines on the IgH S regions, and AID levels roughly correlate with the efficiency of CSR (34). To address whether CTCF regulates the expression of AID during B cell activation, $\mathrm{CTCF}^{\mathrm{f} / \mathrm{fl}}$ and $\mathrm{CTCF}^{\mathrm{fl} /+} \mathrm{B}$ cells were stimulated with LPS + IL-4, and AID levels were assessed by qRT-PCR and 


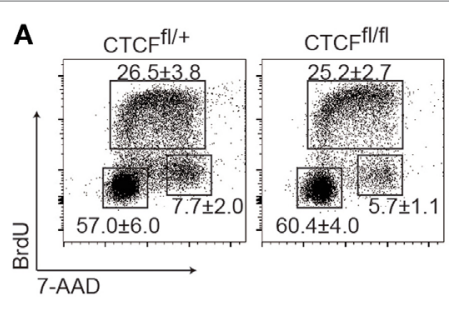

B

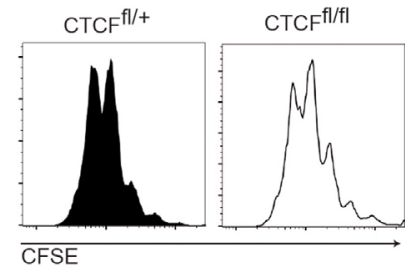

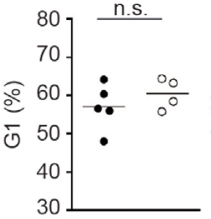
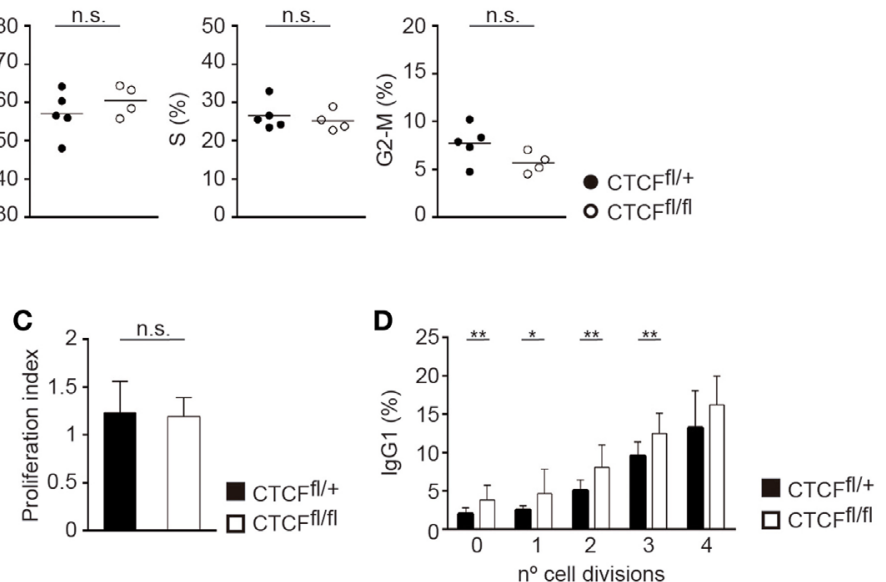

FIGURE 3 | CCCTC-binding factor (CTCF) deficiency does not affect cell proliferation. (A) Cell cycle analysis of spleen B cells from CTCF ${ }^{\mathrm{f} /+}(n=4)$ and CTCF ${ }^{\mathrm{f} / \mathrm{fl}}$ $(n=4)$ mice $48 \mathrm{~h}$ after lipopolysaccharide (LPS) + IL-4 stimulation. DNA content was analyzed by flow cytometry after BrdU incorporation (30 min pulse) and $7-A A D$ staining. Representative plots are shown. Quantification of G1, S, and G2/M phase proportions is shown on the right. (B) CFSE staining of spleen B cells from

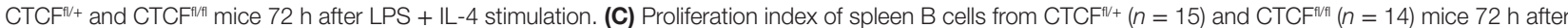
LPS + IL-4 stimulation measured by CFSE. (D) Percentage of IgG1 expression on each cell division measured by CFSE $72 \mathrm{~h}$ after LPS + IL-4 stimulation. $p(0$ division $)=0.0055 ; p$ (1 division $)=0.0298 ; p$ (2 division) $=0.0048 ; p$ (3 division) $=0.005$. Numbers indicate percentages \pm SD. Statistical analysis was done by two-tailed unpaired Student's $t$-test.

western blot analysis. We found that CTCF deficiency did not significantly affect the expression of AID at the mRNA or protein level (Figures 4A,B).

A fraction of AID-induced deaminations on $\mathrm{S}$ regions are processed into DNA double strand breaks, while others give rise to mutations that can be used to track AID activity (33, 35-37). Thus, we next compared the mutation frequency in $\mathrm{S} \mu$ of $\mathrm{CTCF}^{\mathrm{A} / \mathrm{fl}}$ and $\mathrm{CTCF}^{\mathrm{Al} /+} \mathrm{B}$ cells stimulated with LPS + IL-4 by PCR-Seq (32). We found that $S \mu$ regions of $C T C F^{f / / f l} B$ cells accumulated a significantly higher frequency of mutations than $\mathrm{CTCF}^{\mathrm{fl} /+} \mathrm{B}$ cells (Figure 4C). In both CTCF-proficient and-deficient B cells, mutations clustered preferentially at WRCY/ RGYW AID mutational hotspots (38) (Figure 4C) and extended throughout the length of the sequenced region (Figure 4D; Table S1 in Supplementary Material). These findings indicate that AID-induced mutation frequency at $\mathrm{S}$ regions is quantitatively increased in $\mathrm{CTCF}^{\mathrm{A} / \mathrm{fl}} \mathrm{B}$ cells, suggesting that CTCF deficiency could enhance AID activity by facilitating its access to $\mathrm{S}$ regions at IgH. In agreement with this idea, we found that the density of CTCF-binding to the different CBEs interspersed at the IgH locus was altered in LPS/IL-4 stimulated B cells as compared with naïve B cells (39) (Figure 4E). Specifically, we found that several CBEs, such as the $5^{\prime}$ hs $1 \mathrm{R} 1$ site $(29,39)$, and peaks 3 and 7 at the $3^{\prime} \mathrm{RR}$ (Figure 4E) were more densely bound by CTCF in resting than in activated $\mathrm{B}$ cells, while we found no difference or the reverse trend for other CBEs. This analysis indicates that during B cell activation, binding of CTCF to the IgH is rearranged, suggesting that CTCF could be an important factor involved in chromatin remodeling of IgH during B cell activation.

To gain further insights into the role in CTCF in regulating $\operatorname{IgH}$ accessibility, we measured GLT at donor and acceptor $\mathrm{S}$ regions in CTCF-proficient and -deficient B cells. GLT is absolutely required for CSR and is widely considered an indicator of $\mathrm{S}$ region accessibility $(10,11)$. While $S \mu$ is transcribed constitutively, GLT at acceptor $\mathrm{S}$ regions is induced only upon appropriate stimulation of I promoters. We measured GLT at $S$ regions in naïve and stimulated B cells and found that $S \mu$ transcription was not affected in $\mathrm{CTCF}^{\mathrm{f} / \mathrm{fl}} \mathrm{B}$ cells compared to $\mathrm{CTCF}^{\mathrm{f} /+} \mathrm{B}$ cells, regardless of their resting or activated state (Figure 5A). In contrast, GLT expression of $S \gamma 1$ acceptor region was significantly increased in naïve B cells, but not in activated B cells (Figure 5B). Accordingly, GLT- $\gamma 3$ and GLT- $\gamma 2 \mathrm{~b}$ also showed a clear increase in $\mathrm{CTCF}^{\mathrm{f} / \mathrm{fl}}$ naïve B cells when compared to $\mathrm{CTCF}^{\mathrm{f} /+} \mathrm{B}$ cells (Figure $5 \mathrm{C}$ ). Together, these results show that CTCF prevents GLT of $\mathrm{S}$ regions prior to B cell activation, and that CTCF deficiency unleashes transcription from the I promoters in naïve B cells.

\section{DISCUSSION}

In this work, we have assessed the role of CTCF in CSR making use of a conditional mouse model for CTCF depletion in mature B cells $\left(\mathrm{CTCF}^{\mathrm{A} / \mathrm{fl}}\right.$; CD19-Cre $\left.\mathrm{Ci}^{\mathrm{k} /+}\right)$. We previously explored the function of CTCF in germinal center $B$ cells using a different mouse model $\left(\mathrm{CTCF}^{\mathrm{f} / \mathrm{fl}}\right.$; AID-Cre $\left.{ }^{\mathrm{TG} /+}\right)$, which promotes CTCF depletion only after B cell activation and induction of AID expression (22). Thus, in the case of $\mathrm{CTCF}^{\mathrm{l} / \mathrm{fl}} ; \mathrm{CD} 19-\mathrm{Cre}^{\mathrm{ki} /+}$ mice, the levels of CTCF are dramatically reduced already in naïve B cells (Figure 1E), while in $\mathrm{CTCF}^{\mathrm{f} / \mathrm{fl}}$; AID-Cre ${ }^{\mathrm{TG} /+}$ mice CTCF depletion is delayed and dependent on $\mathrm{B}$ cell activation and thus naïve B cells have normal CTCF expression (22). Interestingly, these mouse models have revealed important functional differences upon B cell activation. $\mathrm{CTCF}^{\mathrm{f} / \mathrm{fl}}$; AID-Cre $\mathrm{Cr}^{\mathrm{TG} /+} \mathrm{B}$ cells stimulated in the presence of LPS and IL-4 do not have a detectable phenotype, while $\mathrm{CTCF}^{\mathrm{f} / \mathrm{fl}}$; CD19-Cre $\mathrm{K}^{\mathrm{ki} /+}$ B cells show a compromised cell viability and an increase in CSR. This phenotype is supported by the finding that under these conditions, 
A

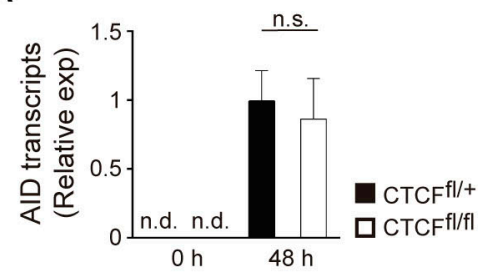

C

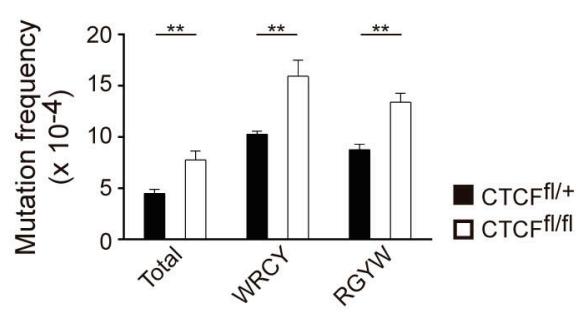

D
B

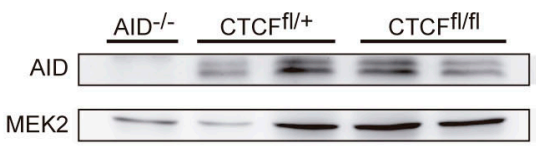

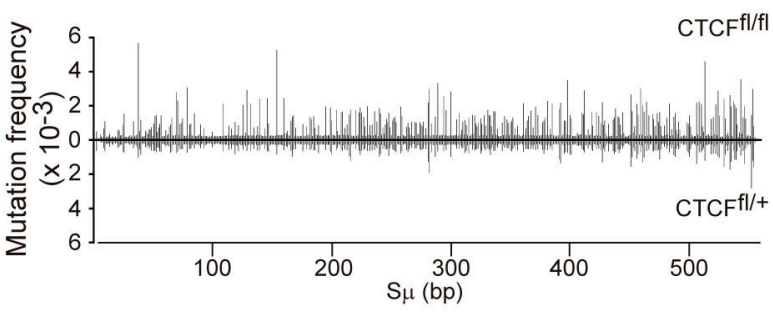

E
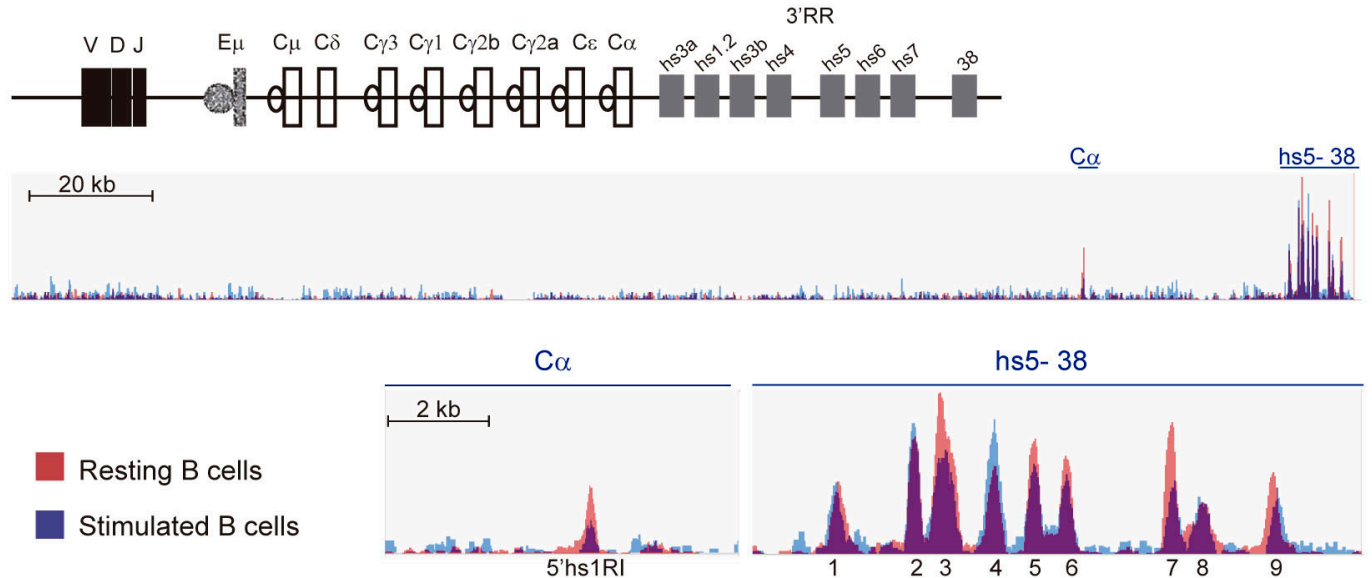

FIGURE 4 | CCCTC-binding factor (CTCF) deletion increases $S$ region somatic mutation and germline transcription. (A) qRT-PCR analysis of activation-induced cytidine deaminase (AID) expression in spleen B cells from $\mathrm{CTCF}^{1 /+}(n=7)$ and $\mathrm{CTCF}^{\mathrm{I} / \mathrm{l}}(n=6)$ mice $48 \mathrm{~h}$ after lipopolysaccharide (LPS) $+\mathrm{IL}-4$ stimulation.

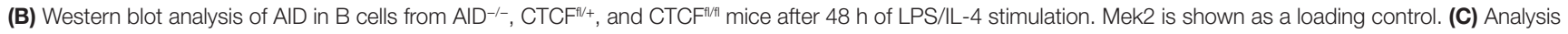
of AID mutagenic activity by next-generation sequencing (32). DNA was isolated from splenic B cells $48 \mathrm{~h}$ after LPS + IL-4 stimulation, amplified by PCR with specific primers and analyzed by next-generation sequencing. Graphs show total mutation frequency, mutation frequency at C or G in WREY/R $\underline{G} Y W$ hotspot motif in $\mathrm{CTCF}^{\mathrm{I} /+}(n=3)$ and $\mathrm{CTCF}^{\mathrm{illi}}(n=3)$ mice. $p($ total $)=0.0039 ; p(\mathrm{WRCY})=0.0037 ; p(\mathrm{RGYW})=0.0015$. (D) Distribution of mutations along the sequenced $\mathrm{S} \mu$ region

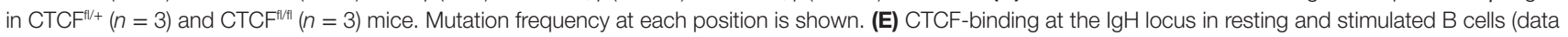
from GSE43594).

the transcriptome of $\mathrm{CTCF}^{\mathrm{f} / \mathrm{fl}}$; AID-Cre ${ }^{\mathrm{TG} /+} \mathrm{B}$ cells are almost intact (22), while LPS/IL-4 stimulated CTCF ${ }^{\mathrm{f} / \mathrm{fl}}$; CD19-Cre $\mathrm{C}^{\mathrm{ki} /+}$ $B$ cells show drastic transcriptome alterations (our unpublished data). Thus, on one hand, these alternative genetic models have unveiled distinct contributions of CTCF at early and late stages of $\mathrm{B}$ cell activation, which will be further investigated. On the other hand, the CTCF fl/fl; CD19-Cre ${ }^{\mathrm{ki} /+}$ model has established an important role of CTCF in the regulation of CSR, the focus of this study.

We have found here that CTCF depletion in $\mathrm{CTCF}^{\mathrm{f} / \mathrm{fl}}$; CD19$\mathrm{Cre}^{\mathrm{ki} /+} \mathrm{B}$ cells increases the rate of CSR to all isotypes tested, and it does so without significantly altering B cell proliferation rate. This is an interesting observation because it is a first hint that, regardless of the potentially broad functional consequences of CTCF depletion, CTCF ${ }^{\mathrm{f} / \mathrm{fl}}$; CD19-Cre $\mathrm{C}^{\mathrm{k} / /+} \mathrm{B}$ cells may have an intrinsic CSR defect. In search for this defect we first assessed AID levels and found that CTCF has not a noticeable role in the regulation of AID expression. In contrast, we found that the mutation frequency at $S \mu$ is significantly increased in the $\mathrm{CTCF}^{\mathrm{f} / \mathrm{fl}} ; \mathrm{CD} 19-\mathrm{Cre}^{\mathrm{ki} /+} \mathrm{B}$ cells, suggesting that the accessibility of AID to the switch regions is enhanced in the absence of CTCF. In agreement with this hypothesis, we find that $\mathrm{B}$ cell activation 
A

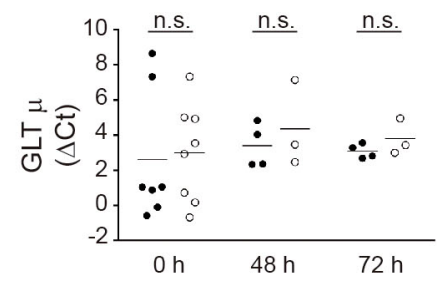

B

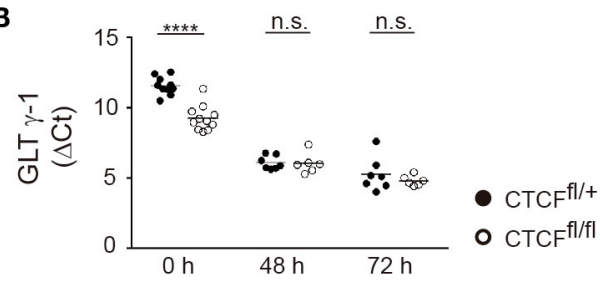

C
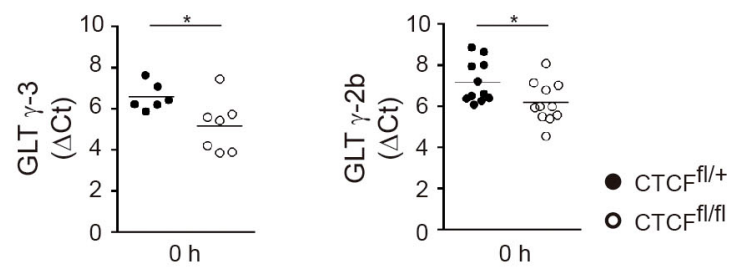

FIGURE 5 | CCCTC-binding factor (CTCF) deficiency enhances germline transcription (GLT) in resting B cells. (A,B) qRT-PCR analysis of germline transcript $\mu$ (A),

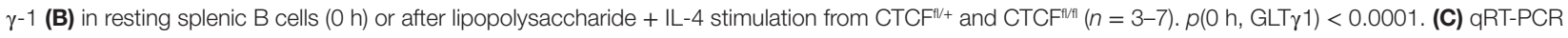
analysis of germline transcript $\gamma-3$ (left), $\gamma$-2b (right) in resting splenic B cells. $p(0 \mathrm{~h}, \mathrm{GLT} \gamma 3)=0.0353 ; p(0 \mathrm{~h}, \mathrm{GLT} \gamma 2 \mathrm{~b})=0.0307$. Data are shown as the $\Delta \mathrm{Ct}$ value calculated from the difference in the Ct of the GLT and GAPDH. Statistical analysis was done with two-tailed unpaired Student's $t$-test.

results in a redistribution of CTCF-binding along the IgH locus, and that GLT is increased in CTCF-deficient naïve B cells.

Although we cannot rule out that CTCF could also restrict CSR by the transcriptional silencing of factors, other than AID, important to trigger GLT or to process AID-induced lesions, our data strongly suggest that CTCF restricts GLT and CSR by its interaction with $\mathrm{CBE}$ s found in the IgH locus. In this regard, our findings are reminiscent of recent data that made use of a complementary approach (29). Specifically, Khamlichi and coworkers generated mice with a germline deletion of a DNAseI hypersensitivity site along with a CBE ( $5^{\prime}$ hs $\left.1 \mathrm{R} 1\right)$ and found activation of GLT at various $\mathrm{S}$ regions in naïve $\mathrm{B}$ cells and isotype-specific alterations of CSR after B cell activation. These data suggest that 5'hs1R1 contains a CBE acting as a CTCF insulator that precludes premature activation of I promoters in S regions (29). Likewise, our data strongly suggest that CTCF binds to CBEs at IgH, preventing GLT prior to $\mathrm{B}$ cell stimulation. Dissecting the contribution of specific CBEs and CTCF-mediated chromatin loops to particular CSR phenotypic effects is an essential issue remaining. First, it will be important to precisely define the CTCF-dependent loops taking place before and after $\mathrm{B}$ cell activation by $3 \mathrm{C}$-as previously described for CSR synapsis (40). This should be complemented with functional analysis performing individual and combined deletion of CBEs; this will prove a very challenging task, given the complex array of CBEs at the constant region of IgH-including at least the 5'hs1R1 CBE and nine CBEs downstream of the 3'RR.

The finding that CTCF depletion promotes increase of GLT in resting but not activated $B$ cells is intriguing. We speculate that CTCF contributes to establish a chromatin architecture that keeps the I promoters silent prior to CSR. Unleashing this architectural constraint in naive B cells by depleting CTCF may facilitate the early loading or pre-poising of CSR cofactors that could allow faster or better loading of AID and additional CSR components at the time of activation. Although this hypothesis would require experimental testing, it agrees with previous observations made upon depletion of the 5'hs1R1 CBE (29).

In sum, our results are compatible with a model where CTCF maintains the IgH locus in a locked architectural conformation in naïve B cells that blocks GLT and AID access to $S$ regions, thus preventing premature CSR.

\section{ETHICS STATEMENT}

All animal procedures were conducted according to EU Directive 2010/63/UE, enforced in Spanish law under Real Decreto $53 / 2013$. The procedures have been reviewed by the IACUC of Centro Nacional de Investigaciones Cardiovasculares and approved by Consejeria de Medio Ambiente, Administración Local y Ordenación del Territorio of Comunidad de Madrid (Ref: PROEX 341/14).

\section{AUTHOR CONTRIBUTIONS}

EM-Z and AP-G designed experiments, performed experiments, and wrote manuscript. AR designed experiments and wrote the manuscript.

\section{ACKNOWLEDGMENTS}

The authors thank all members of the B Cell Biology Laboratory, J Méndez and VG de Yébenes for critical reading of the manuscript, F Álvarez-Prado for help with sequence analysis, F Sanchez-Cabo for advise on statistics analysis, and $\mathrm{N}$ Galjart and $\mathrm{K}$ Rajewsky for kindly providing the $\mathrm{CTCF}^{\mathrm{A} /+}$ and the CD19-Cre ${ }^{\mathrm{ki} /+}$ mice, respectively. AP-G was a fellow of the research training program (FPU-AP2009-1732) funded 
by the Ministerio de Educación, Cultura y Deporte; EM-Z is a fellow of the research training program (FPI) funded by the Ministerio de Economía y Competitividad (BES-2014-069525); $\mathrm{AR}$ is supported by Centro Nacional de Investigaciones Cardiovaculares (CNIC). This work was funded with the following grants to AR: SAF2013-42767-R and SAF2016-75511-R (Plan Estatal de Investigación Científica y Técnica y de Innovación 2013-2016 Programa Estatal de I+D+i Orientada a los Retos de la Sociedad Retos Investigación: Proyectos I+D+i 2016, Ministerio de Economía, Industria y Competitividad) and co-funding by Fondo Europeo de Desarrollo Regional (FEDER) and the European Research Council Starting Grant program

\section{REFERENCES}

1. Rajewsky K. Clonal selection and learning in the antibody system. Nature (1996) 381:751-8. doi:10.1038/381751a0

2. Jung D, Giallourakis C, Mostoslavsky R, Alt FW. Mechanism and control of $\mathrm{V}(\mathrm{D}) \mathrm{J}$ recombination at the immunoglobulin heavy chain locus. Annu Rev Immunol (2006) 24:541-70. doi:10.1146/annurev.immunol.23.021704.115830

3. Schatz DG, Ji Y. Recombination centres and the orchestration of V(D)J recombination. Nat Rev Immunol (2011) 11:251-63. doi:10.1038/nri2941

4. Casellas R, Basu U, Yewdell WT, Chaudhuri J, Robbiani DF, Di Noia JM. Mutations, kataegis and translocations in B cells: understanding AID promiscuous activity. Nat Rev Immunol (2016) 16:164-76. doi:10.1038/ nri.2016.2

5. Di Noia JM, Neuberger MS. Molecular mechanisms of antibody somatic hypermutation. Annu Rev Biochem (2007) 76:1-22. doi:10.1146/annurev. biochem.76.061705.090740

6. Muramatsu M, Kinoshita K, Fagarasan S, Yamada S, Shinkai Y, Honjo T. Class switch recombination and hypermutation require activation-induced cytidine deaminase (AID), a potential RNA editing enzyme. Cell (2000) 102:553-63. doi:10.1016/S0092-8674(00)00078-7

7. Victora GD, Nussenzweig MC. Germinal centers. Annu Rev Immunol (2012) 30:429-57. doi:10.1146/annurev-immunol-020711-075032

8. Matthews AJ, Zheng S, DiMenna LJ, Chaudhuri J. Regulation of immunoglobulin class-switch recombination: choreography of noncoding transcription, targeted DNA deamination, and long-range DNA repair. Adv Immunol (2014) 122:1-57. doi:10.1016/B978-0-12-800267-4.00001-8

9. Stavnezer J, Guikema JE, Schrader CE. Mechanism and regulation of class switch recombination. Annu Rev Immunol (2008) 26:261-92. doi:10.1146/ annurev.immunol.26.021607.090248

10. Matthews AJ, Zheng S, DiMenna LJ, Chaudhuri J. Regulation of immunoglobulin class-switch recombination. Adv Immunol (2014) 122:1-57. doi:10.1016/ B978-0-12-800267-4.00001-8

11. Pavri R, Nussenzweig MC. AID targeting in antibody diversity. Adv Immunol (2011) 110:1-26. doi:10.1016/B978-0-12-387663-8.00005-3

12. Ong CT, Corces VG. CTCF: an architectural protein bridging genome topology and function. Nat Rev Genet (2014) 15:234-46. doi:10.1038/nrg3663

13. Merkenschlager M, Odom DT. CTCF and cohesin: linking gene regulatory elements with their targets. Cell (2013) 152:1285-97. doi:10.1016/j. cell.2013.02.029

14. Hnisz D, Day DS, Young RA. Insulated neighborhoods: structural and functional units of mammalian gene control. Cell (2016) 167:1188-200. doi:10.1016/j.cell.2016.10.024

15. Majumder P, Gomez JA, Chadwick BP, Boss JM. The insulator factor CTCF controls MHC class II gene expression and is required for the formation of long-distance chromatin interactions. J Exp Med (2008) 205:785-98. doi:10.1084/jem.20071843

16. Splinter E, Heath H, Kooren J, Palstra RJ, Klous P, Grosveld F, et al. CTCF mediates long-range chromatin looping and local histone modification in the beta-globin locus. Genes Dev (2006) 20:2349-54. doi:10.1101/gad.399506

17. Ribeiro de Almeida C, Stadhouders R, de Bruijn MJ, Bergen IM, Thongjuea S, Lenhard B, et al. The DNA-binding protein CTCF limits
(BCLYM-207844). The CNIC is supported by the Ministry of Economy, Industry and Competitiveness (MEIC) and the Pro CNIC Foundation and is a Severo Ochoa Centre of Excellence (MEIC award SEV-2015-0505).

\section{SUPPLEMENTARY MATERIAL}

The Supplementary Material for this article can be found online at http://journal.frontiersin.org/article/10.3389/fimmu.2017.01076/ full\#supplementary-material.

TABLE S1 | The mutation analysis of the $\mathrm{S} \mu$ region $\mathrm{CTCF}^{\mathrm{fl} /+}$ and $\mathrm{CTCF}^{\mathrm{f} / \mathrm{fl}} \mathrm{B} 48 \mathrm{~h}$ after lipopolysaccharide + IL-4 stimulation.

proximal Vkappa recombination and restricts kappa enhancer interactions to the immunoglobulin kappa light chain locus. Immunity (2011) 35:501-13. doi:10.1016/j.immuni.2011.07.014

18. Degner SC, Verma-Gaur J, Wong TP, Bossen C, Iverson GM, Torkamani A, et al. CCCTC-binding factor (CTCF) and cohesin influence the genomic architecture of the Igh locus and antisense transcription in pro-B cells. Proc Natl Acad Sci U S A (2011) 108:9566-71. doi:10.1073/pnas.1019391108

19. Guo C, Yoon HS, Franklin A, Jain S, Ebert A, Cheng HL, et al. CTCF-binding elements mediate control of V(D)J recombination. Nature (2011) 477:424-30. doi:10.1038/nature10495

20. Lin SG, Guo C, Su A, Zhang Y, Alt FW. CTCF-binding elements 1 and 2 in the Igh intergenic control region cooperatively regulate $\mathrm{V}(\mathrm{D}) \mathrm{J}$ recombination. Proc Natl Acad Sci U S A (2015) 112:1815-20. doi:10.1073/pnas. 1424936112

21. Hu J, Zhang Y, Zhao L, Frock RL, Du Z, Meyers RM, et al. Chromosomal loop domains direct the recombination of antigen receptor genes. Cell (2015) 163:947-59. doi:10.1016/j.cell.2015.10.016

22. Perez-Garcia A, Marina-Zarate E, Alvarez-Prado AF, Ligos JM, Galjart N, Ramiro AR. CTCF orchestrates the germinal centre transcriptional program and prevents premature plasma cell differentiation. Nat Commun (2017) 8:16067. doi:10.1038/ncomms16067

23. Birshtein BK. The role of CTCF binding sites in the $3^{\prime}$ immunoglobulin heavy chain regulatory region. Front Genet (2012) 3:251. doi:10.3389/ fgene.2012.00251

24. Pinaud E, Marquet M, Fiancette R, Peron S, Vincent-Fabert C, Denizot Y, et al. The IgH locus 3' regulatory region: pulling the strings from behind. $A d v$ Immunol (2011) 110:27-70. doi:10.1016/B978-0-12-387663-8.00002-8

25. Dunnick WA, Shi J, Graves KA, Collins JT. The 3' end of the heavy chain constant region locus enhances germline transcription and switch recombination of the four gamma genes. J Exp Med (2005) 201:1459-66. doi:10.1084/ jem. 20041988

26. Pinaud E, Khamlichi AA, Le Morvan C, Drouet M, Nalesso V, Le Bert M, et al. Localization of the 3' IgH locus elements that effect long-distance regulation of class switch recombination. Immunity (2001) 15:187-99. doi:10.1016/ S1074-7613(01)00181-9

27. Vincent-Fabert C, Fiancette R, Pinaud E, Truffinet V, Cogne N, Cogne M, et al. Genomic deletion of the whole IgH 3' regulatory region (hs3a, hs1,2, hs3b, and hs4) dramatically affects class switch recombination and Ig secretion to all isotypes. Blood (2010) 116:1895-8. doi:10.1182/blood-2010-01264689

28. Volpi SA, Verma-Gaur J, Hassan R, Ju Z, Roa S, Chatterjee S, et al. Germline deletion of Igh 3' regulatory region elements hs 5, 6, 7 (hs5-7) affects $\mathrm{B}$ cell-specific regulation, rearrangement, and insulation of the Igh locus. J Immunol (2012) 188:2556-66. doi:10.4049/jimmunol.1102763

29. Braikia F-Z, Oudinet C, Haddad D, Oruc Z, Orlando D, Dauba A, et al. Inducible CTCF insulator delays the $\mathrm{IgH}$ 3' regulatory region-mediated activation of germline promoters and alters class switching. Proc Natl Acad Sci U S A (2017) 114(23):6092-7. doi:10.1073/pnas.1701631114

30. Heath H, Ribeiro de Almeida C, Sleutels F, Dingjan G, van de Nobelen S, Jonkers I, et al. CTCF regulates cell cycle progression of alphabeta T cells in the thymus. EMBO J (2008) 27:2839-50. doi:10.1038/emboj.2008.214 
31. Rickert RC, Roes J, Rajewsky K. B lymphocyte-specific, Cre-mediated mutagenesis in mice. Nucleic Acids Res (1997) 25:1317-8. doi:10.1093/ nar/25.6.1317

32. Perez-Duran P, Belver L, de Yebenes VG, Delgado P, Pisano DG, Ramiro AR. UNG shapes the specificity of AID-induced somatic hypermutation. J Exp Med (2012) 209:1379-89. doi:10.1084/jem.20112253

33. Reina-San-Martin B, Difilippantonio S, Hanitsch L, Masilamani RF, Nussenzweig A, Nussenzweig MC. H2AX is required for recombination between immunoglobulin switch regions but not for intra-switch region recombination or somatic hypermutation. J Exp Med (2003) 197:1767-78. doi:10.1084/jem.20030569

34. Sernandez IV, de Yebenes VG, Dorsett Y, Ramiro AR. Haploinsufficiency of activation-induced deaminase for antibody diversification and chromosome translocations both in vitro and in vivo. PLoS One (2008) 3:e3927. doi:10.1371/ journal.pone. 0003927

35. Nagaoka H, Muramatsu M, Yamamura N, Kinoshita K, Honjo T. Activationinduced deaminase (AID)-directed hypermutation in the immunoglobulin Smu region: implication of AID involvement in a common step of class switch recombination and somatic hypermutation. J Exp Med (2002) 195:529-34. doi:10.1084/jem.20012144

36. Schrader CE, Bradley SP, Vardo J, Mochegova SN, Flanagan E, Stavnezer J. Mutations occur in the Ig Smu region but rarely in Sgamma regions prior to class switch recombination. EMBO J (2003) 22:5893-903. doi:10.1093/ emboj/cdg550
37. Xue K, Rada C, Neuberger MS. The in vivo pattern of AID targeting to immunoglobulin switch regions deduced from mutation spectra in msh2-/ung-/- mice. J Exp Med (2006) 203:2085-94. doi:10.1084/jem.20061067

38. Rogozin IB, Kolchanov NA. Somatic hypermutagenesis in immunoglobulin genes. II. Influence of neighbouring base sequences on mutagenesis. Biochim Biophys Acta (1992) 1171:11-8. doi:10.1016/0167-4781(92)90134-L

39. Thomas-Claudepierre A-S, Schiavo E, Heyer V, Fournier M, Page A, Robert I, et al. The cohesin complex regulates immunoglobulin class switch recombination. J Exp Med (2013) 210:2495-502. doi:10.1084/jem.20130166

40. Wuerffel R, Wang L, Grigera F, Manis J, Selsing E, Perlot T, et al. S-S synapsis during class switch recombination is promoted by distantly located transcriptional elements and activation-induced deaminase. Immunity (2007) 27:711-22. doi:10.1016/j.immuni.2007.09.007

Conflict of Interest Statement: The authors declare that the research was conducted in the absence of any commercial or financial relationships that could be construed as a potential conflict of interest.

Copyright @ 2017 Marina-Zárate, Pérez-García and Ramiro. This is an open-access article distributed under the terms of the Creative Commons Attribution License (CC BY). The use, distribution or reproduction in other forums is permitted, provided the original author(s) or licensor are credited and that the original publication in this journal is cited, in accordance with accepted academic practice. No use, distribution or reproduction is permitted which does not comply with these terms. 